\title{
Les soins seront plus chers mais toujours abordables
}

\section{Jürg Schlup}

Dr méd., président de la FMH

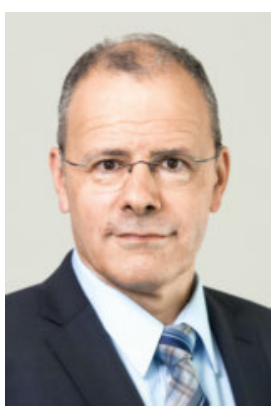

Les références se trouvent

sous www.bullmed.ch

$\rightarrow$ Numéro actuel ou

$\rightarrow$ Archives $\rightarrow 20168 \rightarrow 26 / 27$
A l'heure où le débat sur la prise en charge médicale se focalise avant tout sur les coûts, être médecin sans être économiste n'est pas un avantage. Démasquer les déclarations politiques les plus saugrenues du point de vue économique est d'autant plus difficile. A première vue, l'argument le plus populaire aujourd'hui paraît plausible: les coûts de la santé ne devraient pas augmenter plus vite que les revenus, sinon ils risquent de devenir inabordables. Pour y remédier, il suffirait d'introduire un plafonnement des coûts. Mais est-ce réaliste sans refuser certains traitements? Est-ce vraiment pertinent?

Heureusement, certains économistes sont capables d'expliquer simplement des situations complexes. En 2012 par exemple, William J. Baumol [1], professeur à Princeton, a publié un livre dans lequel il développe la thèse déjà établie en 1966 de la "maladie des coûts», selon laquelle les dépenses de santé doivent fatalement augmenter, tout en restant abordables. Deux professeurs d'économie expliquent cet effet Baumol dans un article qui mérite d'être lu dans ce numéro du BMS à la page 874 [2].

L'idée centrale de Baumol, qui se focalise sur la productivité, est que celle-ci augmente régulièrement, dans le secteur qu'on appelle le secteur progressif, grâce à l'automatisation qui génère une hausse continue du rendement horaire, alors que dans d'autres domaines professionnels, appelés secteur archaïque, le temps de

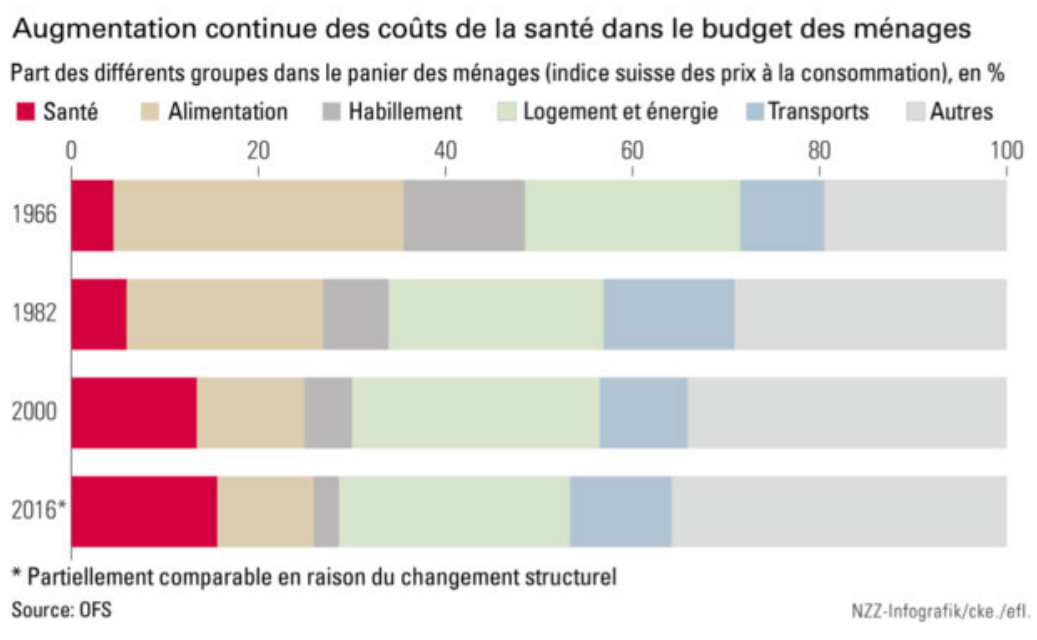

travail humain n'est guère réductible. Si un sac de pommes de terre, une veste ou une voiture exigent de moins en moins de temps de travail, ce dernier sera exactement le même qu'il y a cent ans pour une représentation de théâtre, l'alimentation d'une personne dépendante ou un entretien avec un patient. Les biens du secteur archaïque doivent logiquement renchérir par rapport à ceux du secteur progressif. De ce fait, nous devons dépenser toujours plus pour les soins de santé et d'autres services difficiles à automatiser, et moins pour la plupart des biens de consommation. Enfin, et c'est la bonne nouvelle, la société pourra toujours financer la santé, malgré l'augmentation des coûts, car la hausse de productivité augmente le pouvoir d'achat et le niveau de vie.

Quelques chiffres permettent de visualiser cette évolution: en 1966, un ménage suisse consacrait 30\% de son budget à l'alimentation et 13\% à l'habillement; en 2016, ce n'était plus que 10 et $2 \%$ [3]. Il dispose donc de plus d'argent pour d'autres dépenses. De la même manière, Helsana indique qu'entre 2006 et 2014, les primes ont augmenté de CHF 100 et l'épargne de CHF 715 par mois [4].

Peut-on en conclure qu'il n'y a aucun problème avec les coûts de la santé? Non! Même si dans son ensemble notre société peut se permettre ces dépenses, n'oublions pas qu'il s'agit d'une moyenne [2, 4]. Les augmentations de primes concernent tout le monde, mais tous ne bénéficient pas de hausses de revenu égales. Politiquement, il serait pertinent de mieux répartir les charges. Par contre, plafonner les dépenses de santé financées de manière solidaire est la pire réponse possible: le rationnement induit pénaliserait avant tout ceux qui ne peuvent pas subvenir seuls aux prestations les plus coûteuses.

Léconomiste Baumol a mis en garde contre le fait que des personnes n'auraient plus accès à des prestations importantes parce qu'elles semblent inabordables. Il est donc capital que cet effet soit compris par les milieux politiques, d'autant plus qu'une limitation des prestations de santé impacterait une grande majorité de la population.

\section{Crédit graphique}

NZZ, «Politik muss Debatte über Zweiklassenmedizin aushalten», numéro du 29.9.2017, page 13, avec l'aimable autorisation de la NZZ 